Article

\title{
Novel Class of Chalcone Oxime Ethers as Potent Monoamine Oxidase-B and Acetylcholinesterase Inhibitors
}

\author{
Jong Min Oh ${ }^{1}$, T. M. Rangarajan ${ }^{2, *(\mathbb{D})}$, Reeta Chaudhary ${ }^{3,4}$, Rishi Pal Singh ${ }^{2}$, Manjula Singh ${ }^{5}$, \\ Raj Pal Singh ${ }^{3}$, Anna Rita Tondo ${ }^{6}$, Nicola Gambacorta ${ }^{6}$, Orazio Nicolotti ${ }^{6}$, Bijo Mathew ${ }^{7, *}$ and \\ Hoon Kim ${ }^{1, *(1)}$ \\ 1 Department of Pharmacy, and Research Institute of Life Pharmaceutical Sciences, Sunchon National \\ University, Suncheon 57922, Korea; ddazzo005@naver.com \\ 2 Department of Chemistry, Sri Venketeswara College, University of Delhi, New Delhi-110021, India; \\ rpsingh54@gmail.com \\ 3 Centre for Fire, Explosive and Environment Saftey, DRDO, Delhi-110054, India; \\ chaudhary.reeta90@gmail.com (R.C.); rajcfees@gmail.com (R.P.S.) \\ 4 Department of Chemistry, University of Dehli, Dehli-110007, India \\ 5 Department of Chemistry, Shivaji College, University of Delhi, New Delhi-110027, India; \\ manjulasingh56@gmail.com \\ 6 Dipartimento di Farmacia-Scienze del Farmaco, Università degli Studi di Bari “Aldo Moro", via E. \\ Orabona, 4, I-70125 Bari, Italy; annarita.tondo@gmail.com (A.R.T.); nicola.gambacorta1@uniba.it (N.G.); \\ onicolotti@gmail.com (O.N.) \\ 7 Division of Drug Design and Medicinal Chemistry Research Lab, Department of Pharmaceutical Chemistry, \\ Ahalia School of Pharmacy, Palakkad-678557, Kerala, India \\ * Correspondence: rangarajan93150@gmail.com (T.M.R.); bijo.mathew@ahalia.ac.in (B.M.); \\ hoon@sunchon.ac.kr (H.K.)
}

Received: 24 April 2020; Accepted: 13 May 2020; Published: 18 May 2020

\begin{abstract}
Previously synthesized novel chalcone oxime ethers (COEs) were evaluated for inhibitory activities against monoamine oxidases (MAOs) and acetylcholinesterase (AChE). Twenty-two of the 24 COEs synthesized, except COE-17 and COE-24, had potent and/or significant selective inhibitory effects on MAO-B. COE-6 potently inhibited MAO-B with an $\mathrm{IC}_{50}$ value of $0.018 \mu \mathrm{M}$, which was $105,2.3$, and 1.1 times more potent than clorgyline, lazabemide, and pargyline (reference drugs), respectively. COE-7, and COE-22 were also active against MAO-B, both had an $\mathrm{IC}_{50}$ value of $0.028 \mu \mathrm{M}$, which was 67 and 1.5 times lower than those of clorgyline and lazabemide, respectively. Most of the COEs exhibited weak inhibitory effects on MAO-A and AChE. COE-13 most potently inhibited MAO-A $\left(\mathrm{IC}_{50}=0.88 \mu \mathrm{M}\right)$ and also significantly inhibited MAO-B $\left(\mathrm{IC}_{50}=0.13 \mu \mathrm{M}\right)$, and it could be considered as a potential nonselective MAO inhibitor. COE-19 and COE-22 inhibited AChE with $\mathrm{IC}_{50}$ values of 5.35 and $4.39 \mu \mathrm{M}$, respectively. The selectivity index (SI) of COE-22 for MAO-B was higher than that of COE-6 $(\mathrm{SI}=778.6$ vs. 222.2$)$, but the $\mathrm{IC}_{50}$ value $(0.028 \mu \mathrm{M})$ was slightly lower than that of COE-6 $(0.018 \mu \mathrm{M})$. In reversibility experiments, inhibitions of MAO-B by COE-6 and COE-22 were recovered to the levels of reference reversible inhibitors and both competitively inhibited MAO-B, with $\mathrm{K}_{\mathrm{i}}$ values of 0.0075 and $0.010 \mu \mathrm{M}$, respectively. Our results show that COE-6 and COE-22 are potent, selective MAO-B inhibitors, and COE-22 is a candidate of dual-targeting molecule for MAO-B and AChE.
\end{abstract}

Keywords: monoamine oxidase; acetylcholinesterase; chalcones; oximes; kinetics; reversibility 


\section{Introduction}

Alzheimer's disease (AD) is one of the greatest concerns confronting the medical community, and is the fourth leading cause of neurodegenerative disease-related death. Furthermore, AD has been predicted to affect 100 million patients within 30 years [1]. AD accounts for $70 \%$ of all reported cases of dementia, being characterized by cholinergic functional decline, $\beta$-amyloid oligomer formation, and the dysregulations of other cellular processes [2]. Over past years, many efforts have been made to identify the key biochemical events responsible for AD. However, AD is a multifactorial disease and, thus, its management requires the simultaneous modulations of multiple targets [3]. Based on greater understanding of the disease, recent research efforts have increasingly focused on multitarget-drugs that simultaneously bias different biological targets [4].

This novel approach is viewed optimistically, and hybridizations of the pharmacophore subunits of bioactive molecules have already resulted in the identification of multifunctional drugs [5] and, as a result, synthetic drugs, like donepezil, rivastigmine, and tacrine, have been used as structural models for molecular hybridization experiments (Figure 1) [6]. Tacrine was the first cholinesterase (ChE) inhibitor that was approved by the FDA for the treatment of AD. However, the use of tacrine is limited by its side-effects and, thus, searches for more compatible and potent tacrine derivatives continue [7].

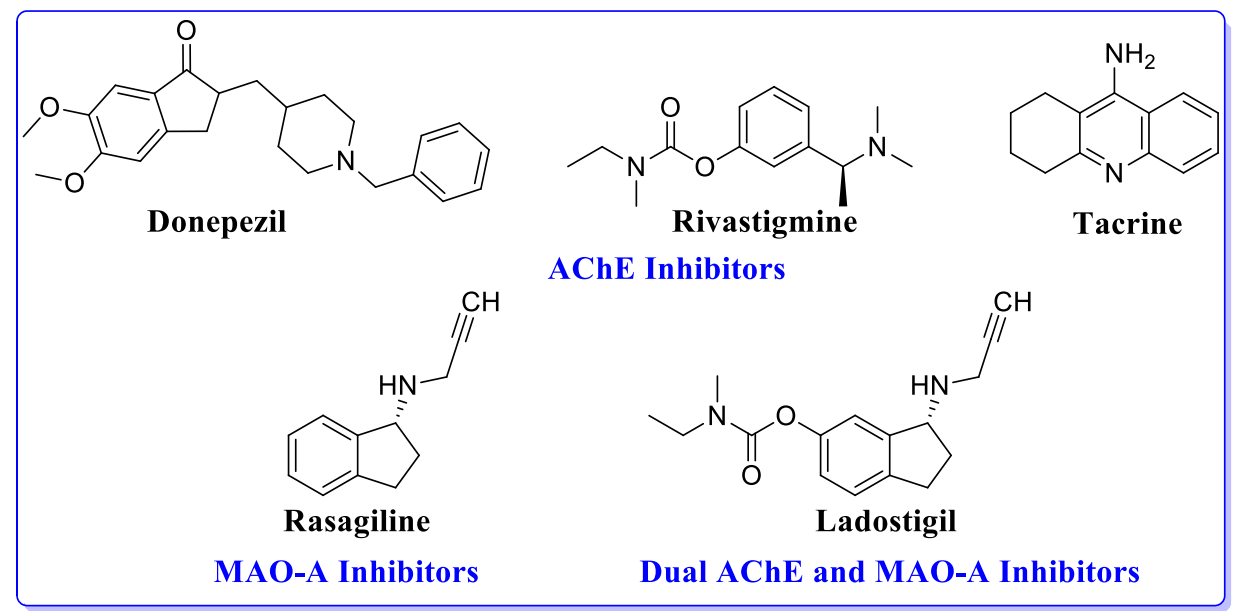

Figure 1. Structures of some FDA approved acetylcholinesterase (AChE) and MAO-A inhibitors.

On the other hand, monoamine oxidase (MAO)-A is primarily targeted for the treatment of depression and anxiety, whereas MAO-B is targeted for AD and Parkinson's disease, based on their specificity, which is, MAO-A prefers serotonin, and MAO-B prefers phenylethylamine and benzylamine [8]. Rasagiline is a MAO inhibitor, and its neuroprotective activity has been attributed to the presence of a propargyl amine moiety, which suppresses the overexpression of Bax protein in AD [9].

The complexity of AD militates against the use of consolidated mono-therapies and supports the notion that dual MAO and acetylcholinesterase (AChE)-inhibitory activities are likely to have better therapeutic effects in AD [10]. Ladostigil is an example of such multi-functional drugs, as it possesses the neuroprotective effects of rasagiline and ChE inhibitory activity (Figure 1) [11]. Notably, most drugs used to treat AD patients in palliative care settings are ChE inhibitors with some multifunctional activity. Furthermore, many studies have shown that MAO inhibitors have attracted considerable research interest in the context of halting or retarding the progression of AD [4].

Chalcones are versatile scaffolds and they are widely distributed in edible plants. Several attempts have been made to synthesize novel biologically active chalcone derivatives due to their wide-ranging biological activities [12-16]. Over recent decades, the MAO-B inhibitory activities of chalcone derivatives have progressively appreciated [17], and many studies have reinforced the 
association between chalcone derivatives and potent MAO-B inhibition [18-35]. Recently, our group reported that ethoxy and ethyl acetohydroxamate (Figure 2) functionalities on chalcone phenyl groups confer significant MAO-B and AChE inhibitory effects [36,37].

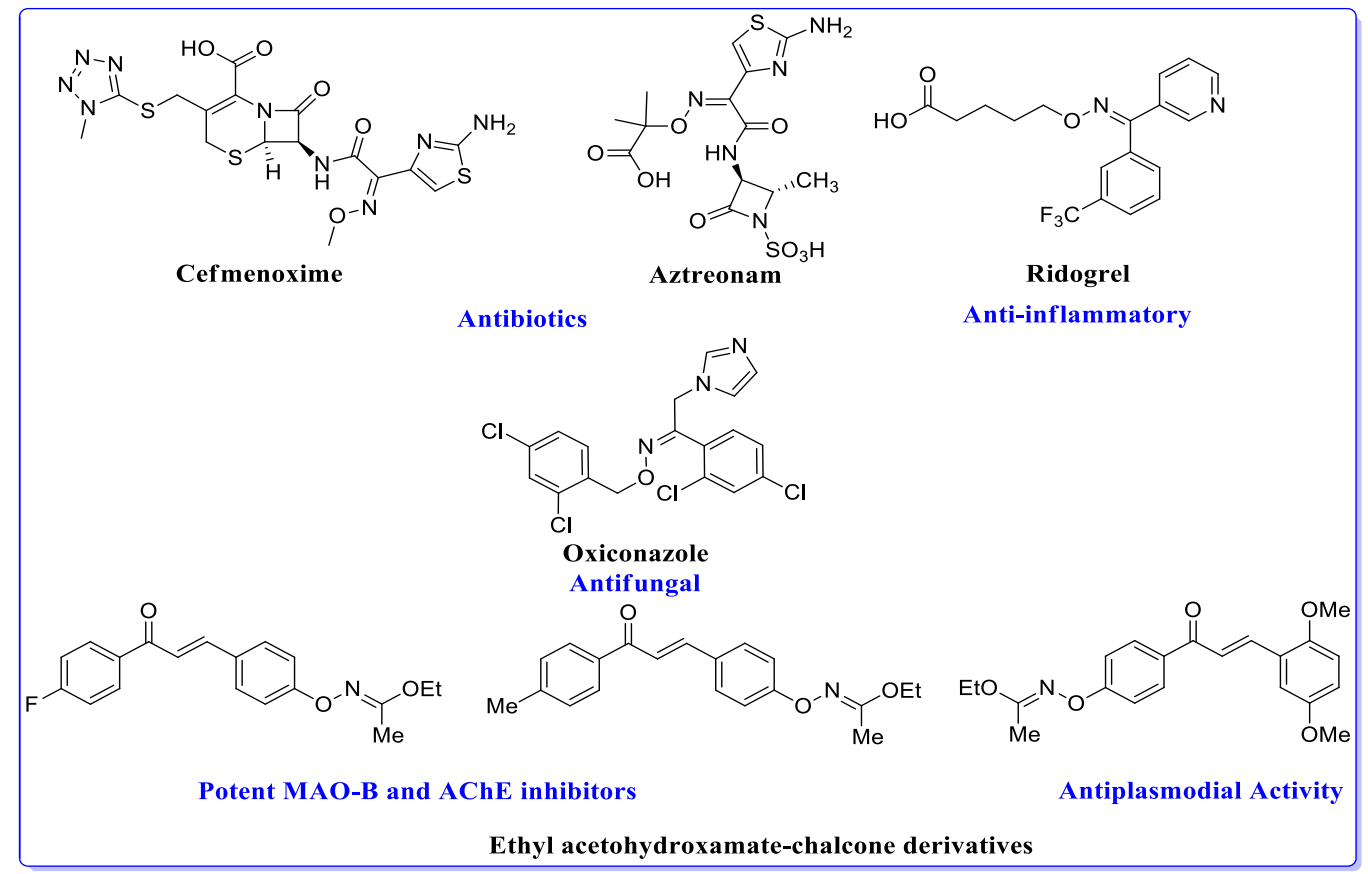

Figure 2. Structures of various biologically active compounds containing oxime moieties.

The oxime ethers are among the most important structural pharmaceutical motifs, for example, they have been associated with transthyretin amyloid fibril formation [38], antibiotic (Cefmenoxime [39], Aztreonam [40], Roxithromycin [41]), anti-inflammatory (Ridogrel) [42], antifungal (Oxiconazole) [43] (Figure 2), and neuroleptic activities [44]. We considered manipulating the ethyl acetohydroxamate functionality in ethyl acetohydroxamate chalcones by introducing an oxime to produce a range of novel chalcone oxime ethers (COEs) with the objective of synthesizing drugs with $\mathrm{MAO}$ and $\mathrm{AChE}$ inhibitory effects for the treatment of AD since oxime ethers have numerous biological properties and ethyl acetohydroxamate chalcones have significant MAO-B and AChE inhibitory [37] (Figure 2) and antiplasmodial [45] effects. Recently, we used Pd-catalyzed C-O cross-coupling reactions between bromo-chalcones and aldoximes [46], or ketoximes [47] in order to synthezise the chalcones, as shown in Scheme 1.

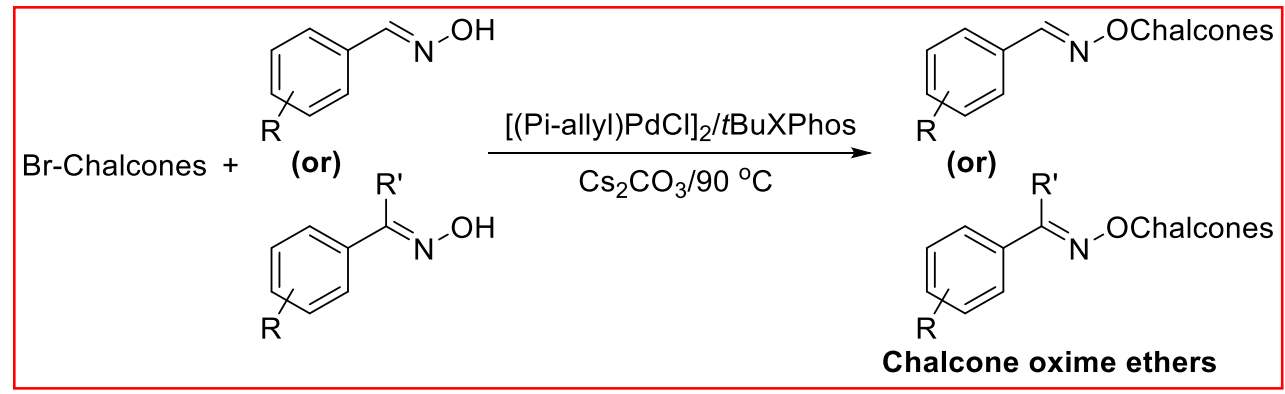

Scheme 1. Pd-catalyzed C-O cross-coupling reactions of bromo-chalcones with oximes.

Herein, we report the abilities of our previously synthesized chalcone ketoxime ethers to inhibit human MAOs (hMAOs) and AChE, kinetics, reversibility, and docking studies. 


\section{Results and Discussion}

\subsection{Synthesis of COEs}

Pd-catalyzed C-O cross-coupling was used to produce $24 \mathrm{COEs}$ by reacting activated aryl bromides, ketoximes, and chalcone oximes together, as shown in Scheme 2, and previously described [47].

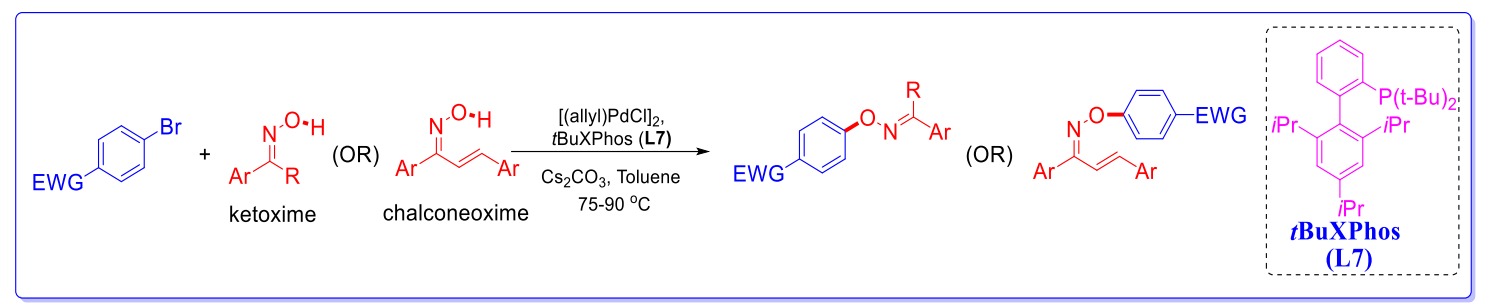

Scheme 2. Pd-catalyzed C-O coupling of activated aryl bromides with ketoximes and chalcone oximes.

The activated aryl bromides included aryl bromides bearing electron-withdrawing groups at the 4-position and bromo-chalcones. Screening phosphine ligands, Pd-catalyst, and solvents was utilized to optimize the method.

\subsection{Inhibitory Activities against $M A O-A, M A O-B$ and $A C h E$}

The MAO-A, MAO-B, and AChE inhibitory activities of 24 synthesized COEs were evaluated while using toloxatone, lazabemide, clorgyline, pargyline, and tacrine as reference molecules (Table 1). The synthesized COEs were of two structural categories, that is, chalcone ketoxime or chalcone-chalcone oxime hybrids. Nineteen of the $24 \mathrm{COEs}$ showed residual MAO-B activities of $<50 \%$ at $1.0 \mu \mathrm{M}$ and potently inhibited MAO-B with $\mathrm{IC}_{50}$ values of $<1.0 \mu \mathrm{M}$ (Table 1). Eight of the 19 showed significant MAO-B inhibitory activities with $\mathrm{IC}_{50}$ values of $<0.1 \mu \mathrm{M}$, and compound COE-6 most potently inhibited MAO-B ( $\left.\mathrm{IC}_{50}=0.018 \mu \mathrm{M}\right)$, and COE-7 and COE-22 had equally significant MAO-B inhibitory activity (both $\mathrm{IC}_{50}=0.028 \mu \mathrm{M}$ ). Interestingly, COE-6 and pargyline had an identical $\mathrm{IC}_{50}$ value $(0.020 \mu \mathrm{M})$ and they were 2.33 and 105.6 times more potent than lazabemide and clorgyline, respectively, and COE-6 was more potent than other chalcone derivatives, (2E)-1-(4-ethoxyphenyl)-3-(4-fluorophenyl) prop-2-en-1-one (E7, $\left.\mathrm{IC}_{50}=0.053 \mu \mathrm{M}\right)$ [36], and ethyl (1E)-N-\{4-[(1E)-3-(4-fluorophenyl)-3-oxoprop-1-en-1-yl]phenoxy\}ethanimidate (L3, $\left.\mathrm{IC}_{50}=0.053 \mu \mathrm{M}\right)$ [37]. Similarly, COE-7 and COE-22 were 1.5 and 68 times more potent than lazabemide and clorgyline, respectively.

Twenty three of the 24 COEs showed residual MAO-A activities of $>60 \%$ at $1.0 \mu \mathrm{M}$, but only COE-13 had a residual activity of $<50 \%$ at $1.0 \mu \mathrm{M}$ (Table 1 ). Twenty-three of the COEs screened relatively weakly inhibited $\mathrm{MAO}-\mathrm{A}\left(\mathrm{IC}_{50}>4.0 \mu \mathrm{M}\right)$. COE-13 had an $\mathrm{IC}_{50}$ value of $0.88 \mu \mathrm{M}$ and it was 1.1 and 2.8 times more potent than toloxatone $\left(\mathrm{IC}_{50}=0.99 \mu \mathrm{M}\right)$ and pargyline $\left(\mathrm{IC}_{50}=2.43 \mu \mathrm{M}\right)$, respectively. COE-13 also significantly inhibited MAO-B $\left(\mathrm{IC}_{50}=0.13 \mu \mathrm{M}\right)$ and, thus, had a low selectivity index (SI) of 6.8. Twenty two of the $24 \mathrm{COEs}$ inhibited MAO-B more than MAO-A, as was reflected by SI values (defined as the ratio of the $\mathrm{IC}_{50}$ values of MAO-A to MAO-B). Of the 24 COEs, only COE-6, COE-7, COE-8, COE-21, and COE-22, had high SI values. Compound COE-8 $\left(\mathrm{IC}_{50}=0.042 \mu \mathrm{M}\right)$ had the lowest SI (182.9), and the most potent MAO-B inhibitor COE-6 $\left(\mathrm{IC}_{50}=0.018 \mu \mathrm{M}\right)$ had the second lowest (222.2). The next most potent MAO-B inhibitors COE-7 and COE-22 (both had an $\mathrm{IC}_{50}$ of $0.028 \mu \mathrm{M}$ ) had SI values of 392.9 and 778.6, respectively, and COE-21 $\left(\mathrm{IC}_{50}=0.036 \mu \mathrm{M}\right)$ had the second highest SI (441.7). This result shows that the chalcone-chalcone oxime hybrids tend to inhibit MAO-B more selectively than chalcone ketoxime hybrids.

AChE inhibition studies showed that only six compounds, COE-5, COE-9, COE-10, COE-19, COE-21, and COE-22, had AChE residual activities of $\angle 50 \%$ at $10 \mu \mathrm{M}$ with $\mathrm{IC}_{50}$ values of $7.06,8.39$, 9.42, 5.35, 9.65, and 4.39 $\mu \mathrm{M}$, respectively. However, AChE inhibitions by these compounds were approximately 22 times less than that of the reference tacrine. COE-22 most potently inhibited AChE 
and also inhibited MAO-B well and it had the highest SI value, which suggest its possible use for the dual-targeting of MAO-B and AChE.

Table 1. Inhibitions of recombinant human MAO-A, MAO-B, and AChE by chalcone oxime ethers ${ }^{\mathrm{a}}$.

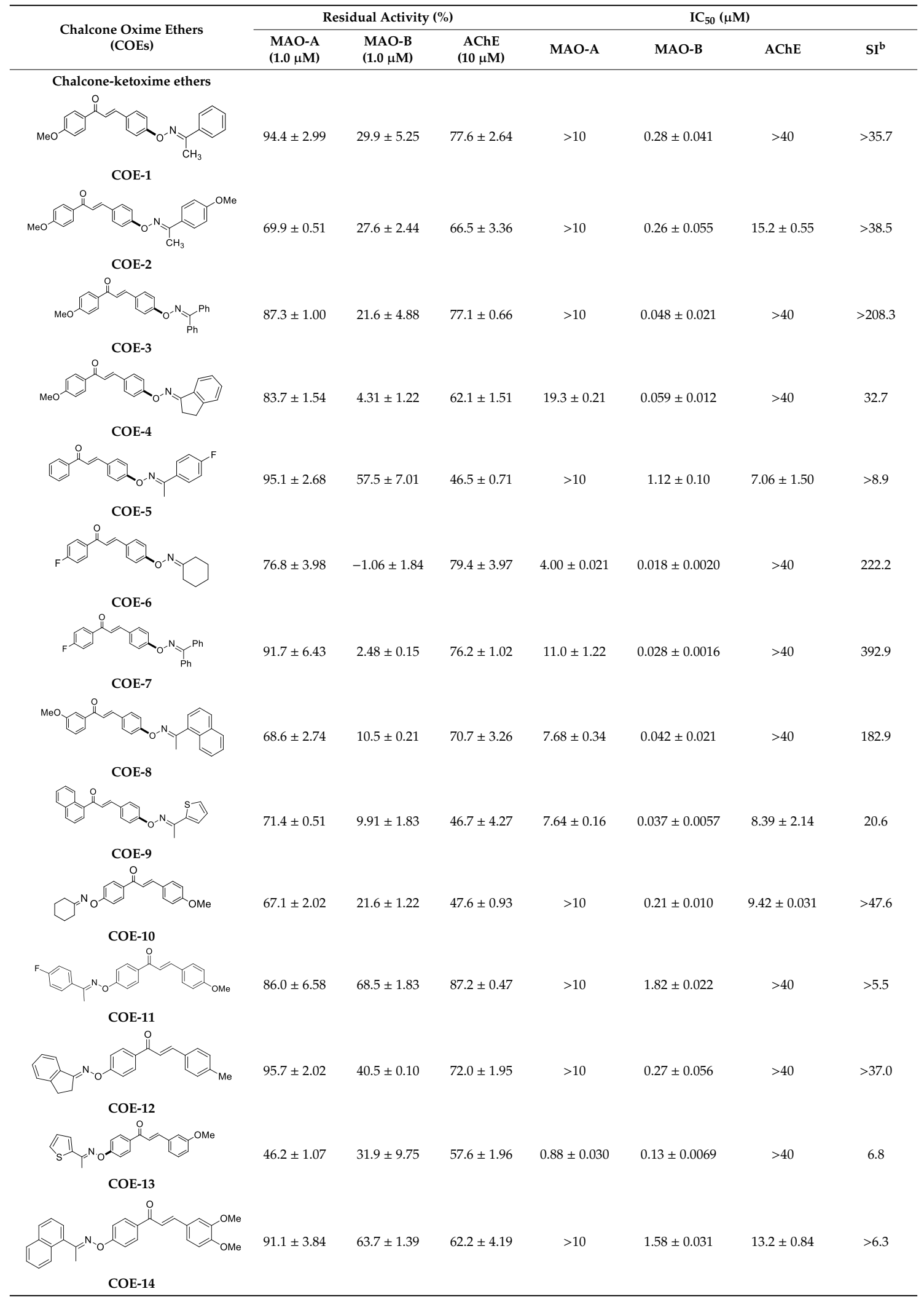


Table 1. Cont.

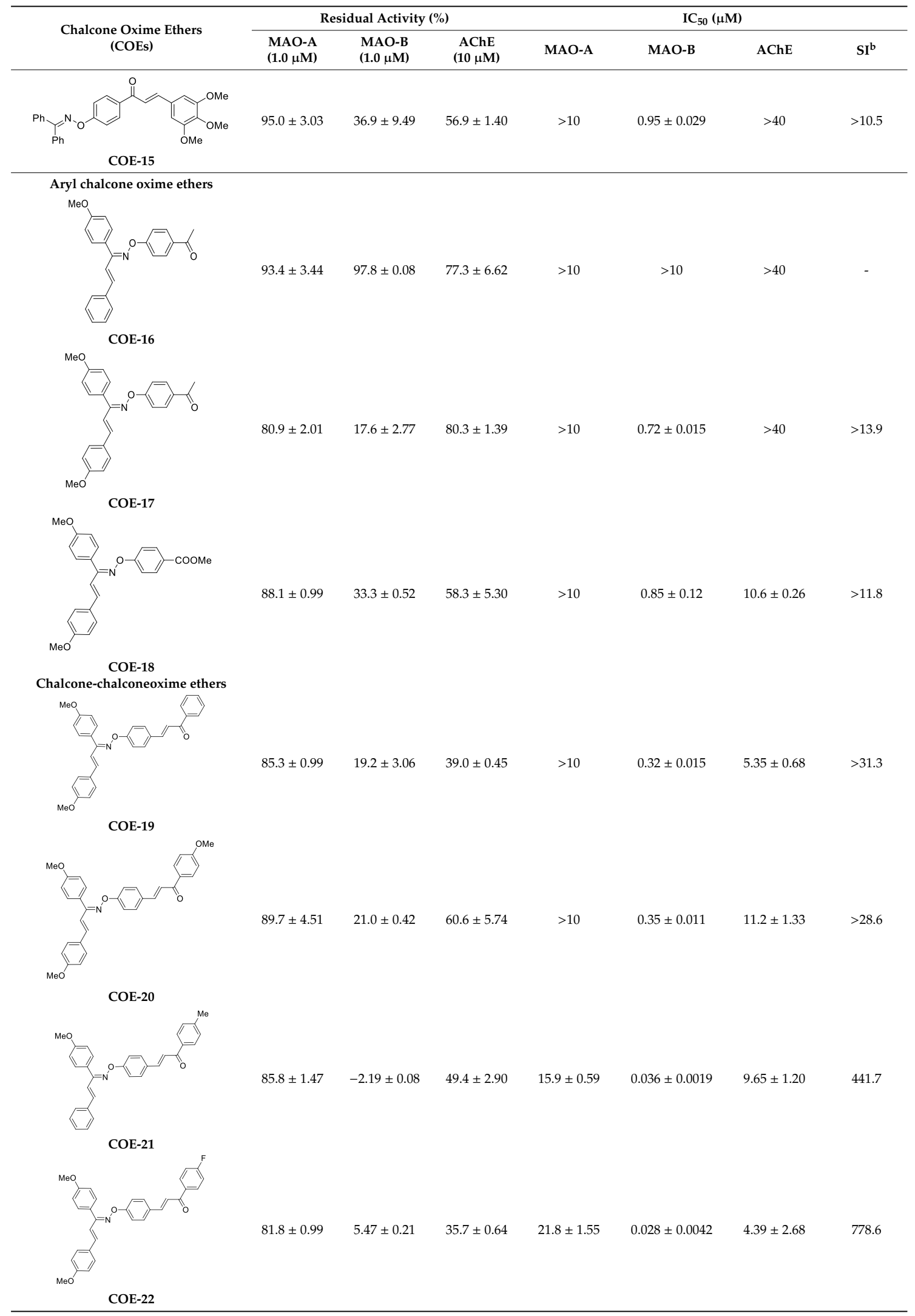


Table 1. Cont.

\begin{tabular}{|c|c|c|c|c|c|c|c|}
\hline \multirow{2}{*}{$\begin{array}{l}\text { Chalcone Oxime Ethers } \\
\text { (COEs) }\end{array}$} & \multicolumn{3}{|c|}{ Residual Activity (\%) } & \multicolumn{4}{|c|}{$\mathrm{IC}_{50}(\mu \mathrm{M})$} \\
\hline & $\begin{array}{l}\text { MAO-A } \\
(1.0 \mu \mathrm{M})\end{array}$ & $\begin{array}{l}\text { MAO-B } \\
(1.0 \mu \mathrm{M})\end{array}$ & $\begin{array}{c}\text { AChE } \\
(10 \mu \mathrm{M})\end{array}$ & MAO-A & MAO-B & $\mathrm{AChE}$ & $\mathrm{SI}^{\mathrm{b}}$ \\
\hline & $85.1 \pm 4.01$ & $25.8 \pm 4.78$ & $57.3 \pm 1.34$ & $>10$ & $0.15 \pm 0.021$ & $9.16 \pm 0.021$ & $>66.7$ \\
\hline COE-23 & & & & & & & \\
\hline & $88.9 \pm 0.98$ & $87.4 \pm 2.81$ & $72.5 \pm 2.91$ & $>10$ & $>10$ & $>40$ & - \\
\hline COE-24 & & & & & & & \\
\hline Toloxatone & - & - & - & $0.99 \pm 0.080$ & - & - & \\
\hline Lazabemide & - & - & - & - & $0.042 \pm 0.0028$ & - & \\
\hline Clorgyline & - & - & - & $\begin{array}{c}0.0046 \pm \\
0.00055\end{array}$ & $1.90 \pm 0.78$ & - & \\
\hline Pargyline & - & - & - & $2.43 \pm 0.17$ & $\begin{array}{l}0.020 \pm \\
0.00071\end{array}$ & - & \\
\hline Tacrine & - & - & - & - & - & $0.20 \pm 0.019$ & \\
\hline
\end{tabular}

${ }^{a}$ Results are expressed as the means \pm standard errors of duplicate experiments. ${ }^{b}$ SI values are expressed as $\mathrm{MAO}-\mathrm{A}$ vs. MAO-B ratios. Results for reference compounds were determined after preincubation with enzymes for $30 \mathrm{~min}$.

\subsection{SARs for Inhibition Studies}

Twenty two of 24 COEs included in the present study were selective MAO-B inhibitors (Table 1). The activity results showed that the activity of the COEs depended on the structures and substituents of oximes and chalcones. For example, in compounds COE-1 to COE-4, structures and the substituent (-OMe) on the chalcone moiety were the same and substituents and structures of oximes differed. The substituents on acetophenone oxime of the chalcone moieties of COE-1 and COE-2 had no meaningful influence on MAO-B inhibition, whereas the conversion of acetophenone oxime (COE-1) to benzophenone oxime (COE-3) and 1-indanone oxime (COE-4) on the chalcone moiety increased MAO-B inhibition by 5.8 and 4.7 times, respectively. Similarly, the removal of -OMe from chalcone and introduction of a $\mathrm{F}$ at the 4-position of acetophenone oxime of COE-1 greatly reduced the MAO-B inhibitory activity of COE-5 $\left(\mathrm{IC}_{50}=1.12 \mu \mathrm{M}\right)$ four-fold. Introduction of $\mathrm{F}$ in place of the -OMe group in chalcone moiety of COE-3 structure $\left(\mathrm{IC}_{50}=0.048 \mu \mathrm{M}\right)$ enhanced the MAO-B inhibitory activity of the compound COE-7 $\left(\mathrm{IC}_{50}=0.028 \mu \mathrm{M}\right)$ 1.7-fold, which suggested that the presence of $\mathrm{F}$ increases MAO-B inhibitory activity more than-OMe group, similar to other chalcone derivatives containing F [48]. Similarly, replacement of the benzophenone oxime of COE-7 with cyclohexanone oxime in COE-6 $\left(\mathrm{IC}_{50}=0.028 \mu \mathrm{M}\right)$ enhanced MAO-B inhibitory activity by 1.5 -fold. The presence of a $\mathrm{F}$ in acetophenone oxime in COE-5 $\left(\mathrm{IC}_{50}=1.12 \mu \mathrm{M}\right)$ and in COE-11 $\left(\mathrm{IC}_{50}=1.82 \mu \mathrm{M}\right)$ reduced MAO-B inhibition, irrespective of the substituents on or the position of oxime in chalcone structure. The position of the 1-acetonaphthone oxime in the chalcone structures of COE-8 $\left(\mathrm{IC}_{50}=0.042 \mu \mathrm{M}\right)$ and COE-14 $\left(\mathrm{IC}_{50}=1.58 \mu \mathrm{M}\right)$ also reduced MAO-B inhibitory activity. Similarly, the position of benzophenone oxime in the chalcone structures of COE-3 $\left(\mathrm{IC}_{50}=0.048 \mu \mathrm{M}\right)$ and COE-15 $\left(\mathrm{IC}_{50}=0.95 \mu \mathrm{M}\right)$ significantly altered MAO-B inhibitory activity. As a result, different ketoxime structures in the benzaldehyde portion of the chalcone structure had significantly greater MAO-B inhibitory activities than ketoxime structures in the acetophenone portion of chalcones. Our SAR study suggested that active oxime groups (e.g., benzophenone oxime, cyclohexanone oxime, acetothiophene oxime, and 1-acetonaphthone oxime) on benzaldehyde portions of chalcones and altering substituents and the structure on the acetophenones portion of chalcones provide a means of enhancing MAO-B inhibitory activities. 
Of the three O-aryl chalcone oximes (COE-16, COE-17, and COE-18), two compounds, COE-17 and COE-18, showed significantly higher MAO-B inhibitory activities $\left(\mathrm{IC}_{50}=0.72\right.$ and $0.85 \mu \mathrm{M}$, respectively) than COE-16 $\left(\mathrm{IC}_{50}>10 \mu \mathrm{M}\right)$. This result implies that the presence of two -OMe groups in the chalcone oxime structure greatly enhances MAO-B inhibition as compared with single-OMe group. Moreover, replacing the $O$-aryl group with an $O$-chalcone group (viz. COE-19 to COE-23) improved the MAO-B inhibitory activity. In the dimethoxy chalcone oxime series, a $\mathrm{F}$ in the acetophenone portion of the chalcone, COE-22, resulted in excellent MAO-B inhibitory activity $\left(\mathrm{IC}_{50}=0.028 \mu \mathrm{M}\right)$, as compared with unsubstituted (-H), COE-19 and -OMe substituted COE-20. The single -OMe substituted chalcone oxime with -Me group in the acetophenone portion of the chalcone moiety of COE-21 also showed significant difference in MAO-B inhibitory activity $\left(\mathrm{IC}_{50}=0.036 \mu \mathrm{M}\right)$. This result suggests that electronegative groups enhance MAO-B inhibitory activity. The acetophenone portion of chalcone containing the -OMe group in COE-20 significantly increased MAO-B inhibitory activity, when compared to the benzaldehyde portion containing the same group in COE-23 (IC $50=0.35$ vs. $0.15 \mu \mathrm{M}$ ). These SAR studies afford great scopes of opportunity to synthesize more potent chalcone-chalcone oxime hybrid molecules, i.e., COEs.

No SAR study could be performed with respect to MAO-A inhibitory activity. Only one compound, COE-13, showed significant MAO-A inhibitory activity with an $\mathrm{IC}_{50}$ value of $0.88 \mu \mathrm{M}$, which in itself suggested that the presence of an acetothiophene oxime group in the acetophenone portion might enhance the MAO-A inhibitory activity. Interestingly, COE-13 also inhibited MAO-A and MAO-B.

Similarly, only compound COE-22, a chalcone-chalcone oxime ether with a -F substituent, inhibited $\mathrm{AChE}\left(\mathrm{IC}_{50}=4.39 \mu \mathrm{M}\right)$. Thus, COE-22 may be considered a MAO-B and AChE dual inhibitor for the treatment of neurodegenerative diseases.

\subsection{Kinetics of $M A O-B$ Inhibitions}

Kinetic studies were performed on MAO-B inhibition by COE-6 and COE-22. Lineweaver-Burk plots and secondary plots showed that COE-6 and COE-22 competitively inhibited MAO-B (Figure $3 \mathrm{~A}, \mathrm{C}$ ) with $\mathrm{K}_{\mathrm{i}}$ values of $0.0075 \pm 0.00067$ and $0.010 \pm 0.0035 \mu \mathrm{M}$, respectively (Figure 3B,D). These results suggest that COE-6 and COE-22 are potent, selective, and competitive inhibitors of MAO-B.

\subsection{Reversibility Studies}

Reversibility studies were conducted on MAO-B inhibition by COE-6 and COE-22. In these experiments, inhibitions of MAO-B by COE-6 and COE-22 were recovered from $19.7\left(\mathrm{~A}_{\mathrm{U}}\right)$ to $81.1 \%\left(\mathrm{~A}_{\mathrm{D}}\right)$ and from $22.6\left(\mathrm{~A}_{\mathrm{U}}\right)$ to $86.8 \%\left(\mathrm{~A}_{\mathrm{D}}\right)$, respectively (Figure 4$)$, and these values were similar to those of the reversible reference inhibitor lazabemide (from 2.4 to $76.4 \%$ ). However, inhibition by the irreversible reference inhibitor pargyline was only slightly recovered (from 3.7 to $10.4 \%$ ). These experiments showed that inhibitions of MAO-B by COE-6 and COE-22 were recovered to the reversible reference level, which suggested that both are reversible inhibitors.

\subsection{Computational Studies}

Computational analyses were performed using QM-polarized docking and MM-GBSA calculations in order to investigate the binding modes of COE-6 and COE-22 towards MAO-A and MAO-B and with the purpose of clarifying the MAO-B selectivity of the two compounds. Table 2 reports calculated docking scores and the $\Delta G$ binding values of the two compounds against MAO-A and MAO-B. In agreement with in vitro $\mathrm{IC}_{50}$ values, $\mathrm{COE}-22$ showed a better docking and MMGBSA scores for MAO-B compared to MAO-A. Conversely, COE-6 did not show a significant gap in the docking score values between MAO-B and MAO-A.

Compound COE-22 interacts with MAO-A and MAO-B with different binding modes (Figure 5). The residues of MAO-A involved in COE-22 binding are Tyr62 and Lys218, which establish $\pi$ and cation- $\pi$ interactions, respectively, with the para-fluorine phenyl ring, Lys341, which engages a hydrogen bond with the carbonyl oxygen atom of the chalcone portion of COE-22, and Lys316, which forms a 
cation- $\pi$ interaction with the para-methoxy phenyl ring, as shown on panel (a) of Figure 5 . Notably, the distance between the para-fluorine phenyl ring and aromatic rings of the flavin adenine dinucleotide (FAD) molecule is $\sim 11 \AA$. On the other hand, as shown on panel (b) of Figure 5, the residues of MAO-B involved in COE-22 binding are similar to those hypothesized in previous studies [25], whereby the para-fluorine phenyl ring of COE-22 is trapped within an aromatic cage made up of FAD, Tyr398, and Tyr435. Furthermore, the para-fluorine phenyl ring, the para-methoxy styryl, and the chalcone aromatic ring establish $\pi-\pi$ interactions with Tyr398, Trp119, and Tyr236 (MAO-B selective residue), respectively. In addition, the carbonyl oxygen of the chalcone scaffold of COE-22 forms a hydrogen bond with the thiol group of Cys172.

(A)

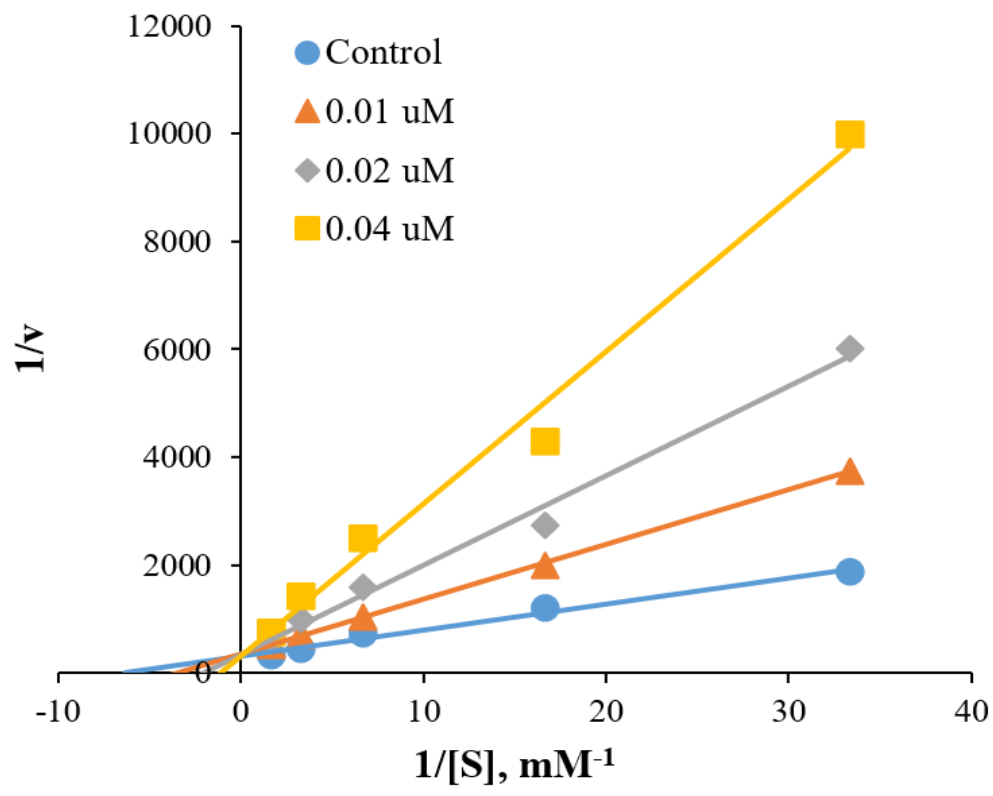

(B)

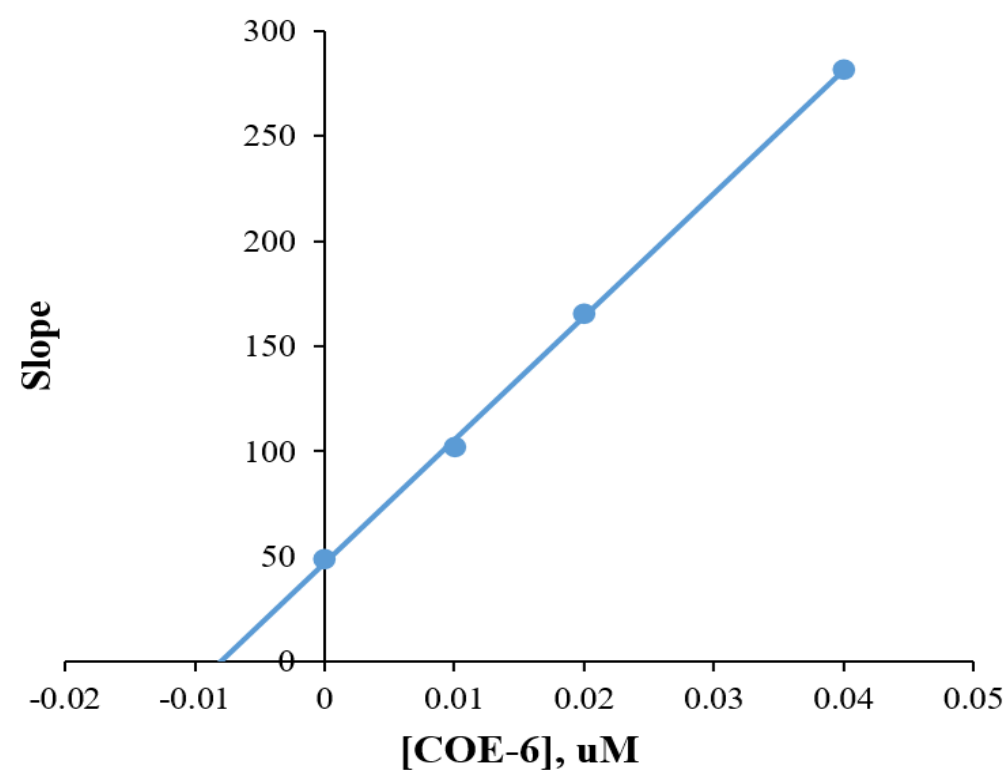

Figure 3. Cont. 
(C)

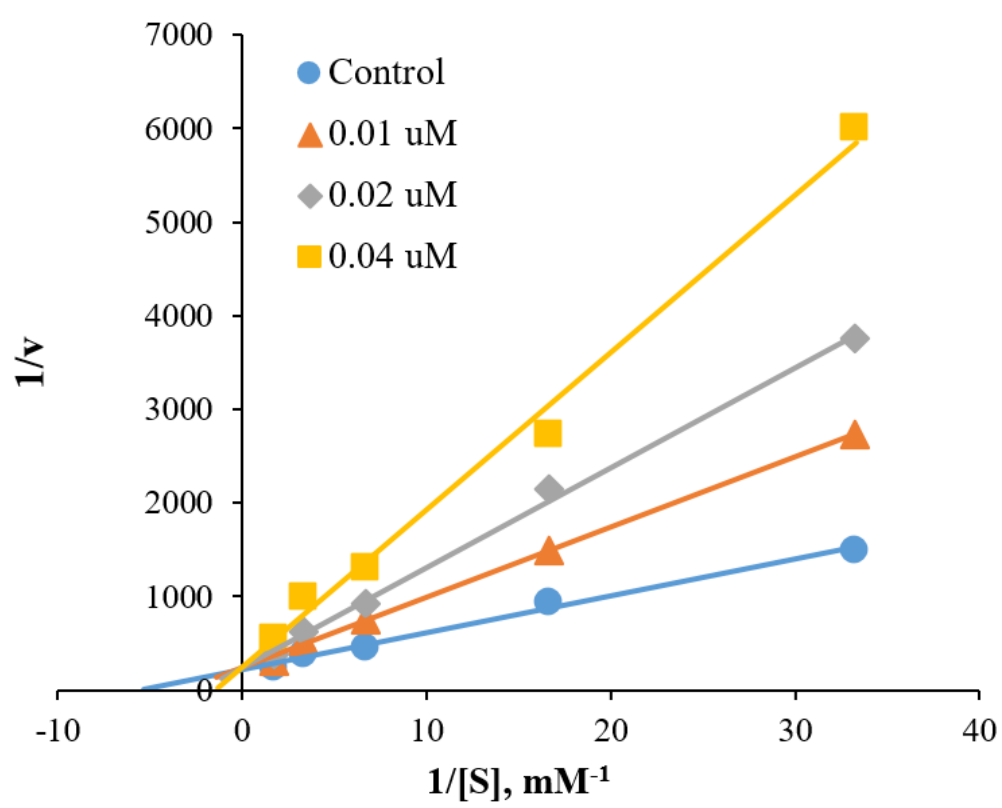

(D)

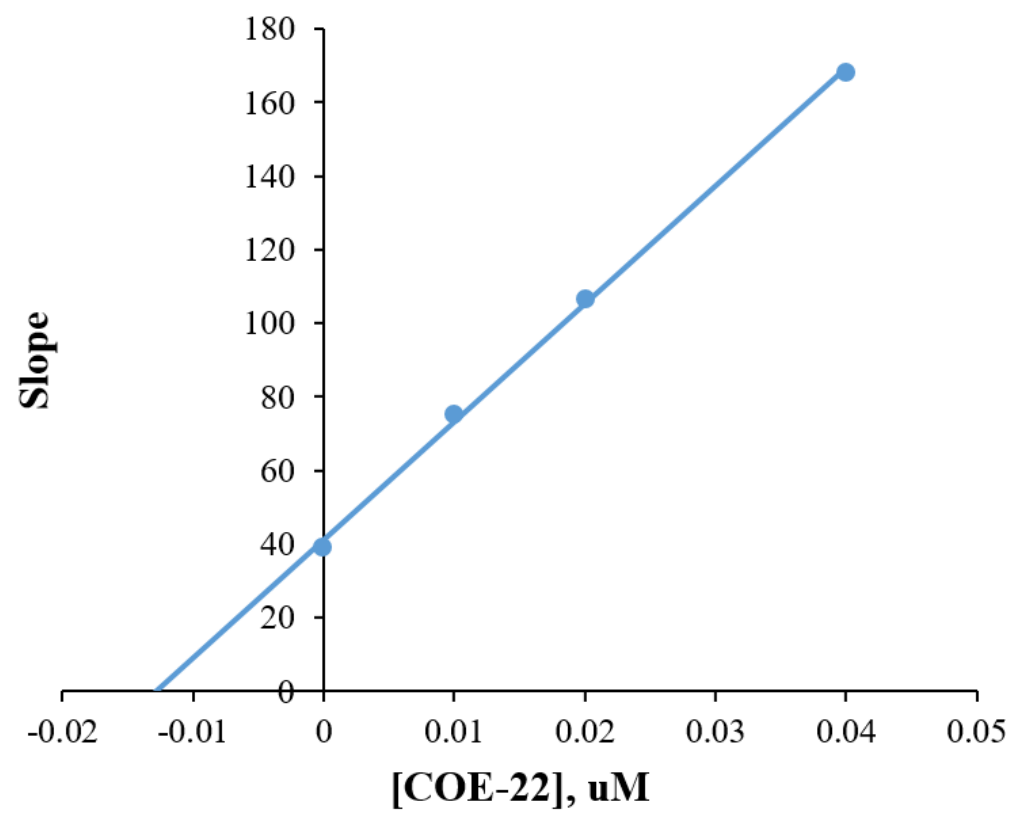

Figure 3. Lineweaver-Burk plots for MAO-B inhibition by COE-6 (A) and COE-22 (C), and their respective secondary plots $(\mathbf{B}, \mathbf{D})$ of slopes vs. inhibitor concentrations.

Table 2. Docking scores and $\Delta \mathrm{G}$ binding values of lead compounds with MAO-A and MAO-B.

\begin{tabular}{ccccc}
\hline \multirow{2}{*}{ Compound } & \multicolumn{2}{c}{ Docking Score $(\mathbf{k c a l} / \mathbf{m o l})$} & \multicolumn{2}{c}{$\Delta G_{\text {binding }}(\mathbf{k c a l} / \mathbf{m o l})$} \\
\cline { 2 - 5 } & MAO-A & MAO-B & MAO-A & MAO-B \\
\hline COE-6 & -10.128 & -11.728 & -58.64 & -82.65 \\
COE-22 & -7.785 & -13.452 & -60.57 & -87.94 \\
\hline
\end{tabular}


Undialyzed Dialyzed

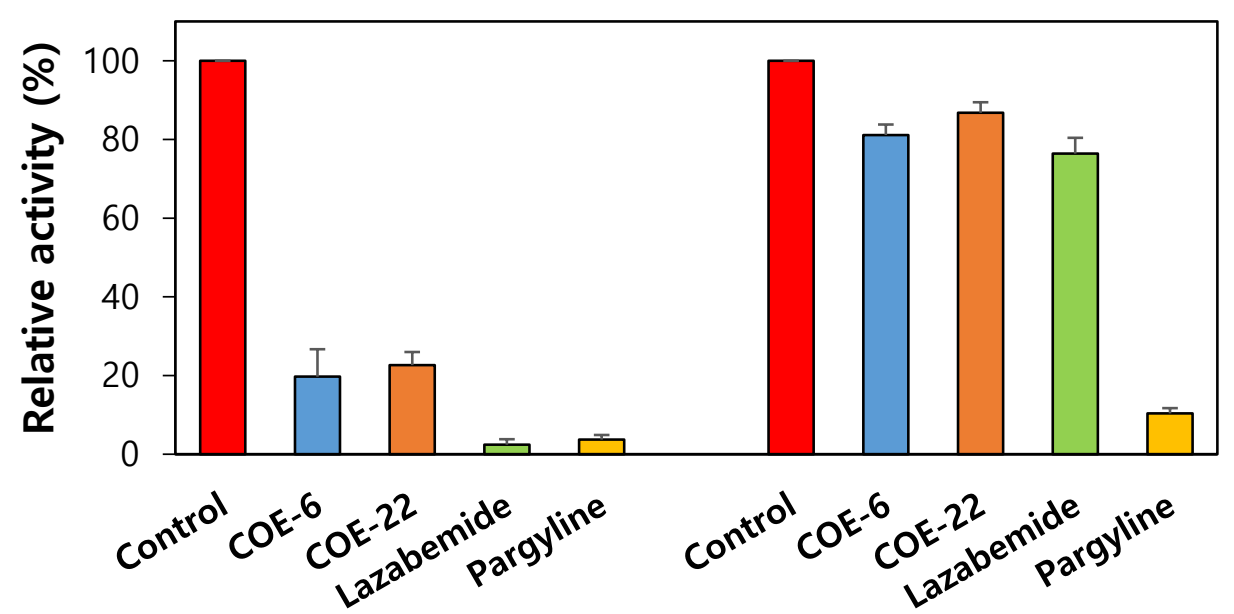

Figure 4. Recoveries of inhibitions of MAO-B by COE-6 and COE-22 as determined by dialysis.

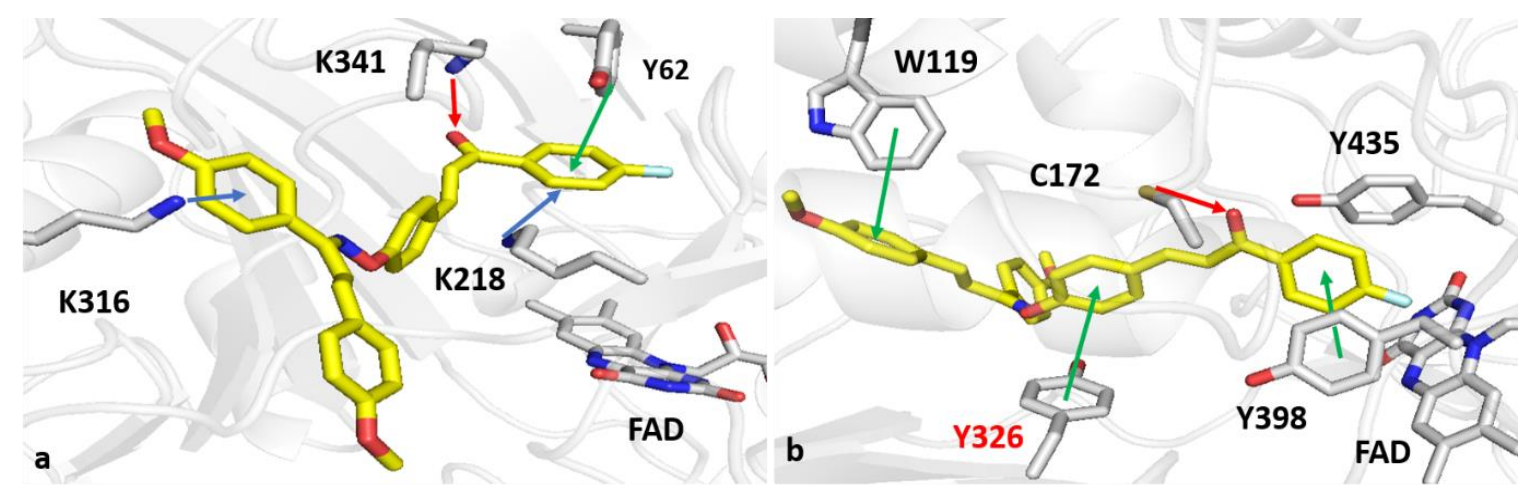

Figure 5. Top scored poses of COE-22 in the binding sites of MAO-A (a) and MAO-B (b). Proteins are rendered as white cartoons, while ligands are rendered as yellow sticks. Green, blue and red arrows indicate $\pi-\pi$ interactions, cation- $\pi$ interactions and hydrogen bonds, respectively. Y326, responsible for MAO-B selectivity, is labeled red.

Docking analysis did not report meaningful differences for interactions of COE-6 towards MAO-A and MAO-B. The para-fluorine phenyl ring of COE-6 is involved in $\pi-\pi$ interaction with Tyr407 of MAO-A, and it is trapped within an aromatic cage delimited by Tyr407, Tyr444, and FAD, unlike COE-22, as shown on panel (a) of Figure 6. When considering MAO-B, the para-fluorine phenyl ring of COE- 6 engages $\pi-\pi$ interaction with Tyr435 and faces the aromatic cage that is formed by Tyr435, Tyr398, and FAD. Notably, the selective MAO-B residue Tyr326 establishes $\pi-\pi$ interaction with the chalcone aromatic ring, and Cys172 makes a hydrogen bond with the carbonyl oxygen of the COE-6 chalcone scaffold.

Docking studies carried out on COE-6 and COE-22 have proved that compound COE-22 had the highest MAO-B affinity and appreciable selectivity. More specifically, COE-22 interacts with MAO-A and MAO-B, but with different binding modes. In particular, in agreement with previous findings [24-29], the chalcone head of COE-22 faces the FAD of MAO-B, whereas COE-6 adopts similar poses for MAO-A and MAO-B, probably because of its smaller size. Interestingly, docking studies successfully explained at the molecular level the different experimental affinities of COE-6 and COE-22 for the two MAO isoforms. In particular, the gain in binding for MAO-B was mostly supported by the chance of forming $\pi-\pi$ hydrophobic interaction with Tyr326. This is a key residue, which changed 
to I335 in MAO-A [49], capable of giving access to the binding pocket (for COE-22 compound) and stabilizing the chalcone aromatic ring.

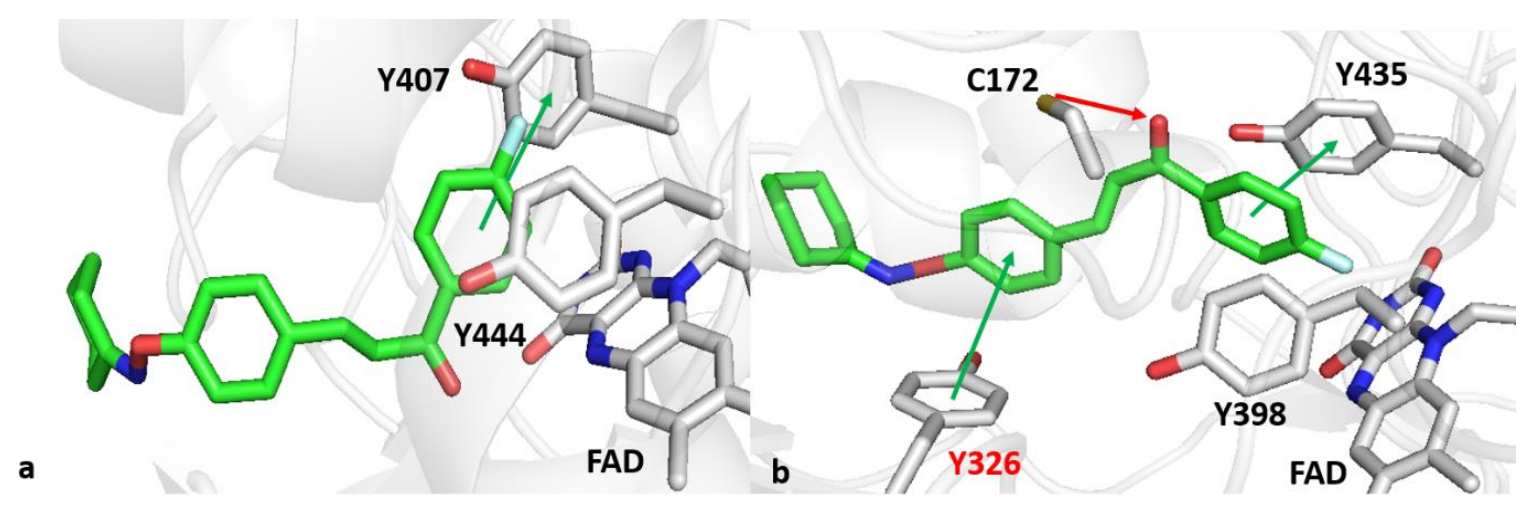

Figure 6. Top scored poses of COE-6 in the binding sites of MAO-A (a) and MAO-B (b). Proteins and COE- 6 are depicted in white cartoons, and green sticks, respectively. Green arrows indicate $\pi-\pi$ interactions. MAO-B selective residue Y326 is highlighted in red.

\section{Materials and Methods}

\subsection{Enzyme Assays}

Recombinant hMAO-A and hMAO-B activities were assayed while using kynuramine $(0.06 \mathrm{mM})$ and benzylamine $(0.3 \mathrm{mM})$ as substrates, respectively, as described previously [50]. The substrate concentrations were $1.7 \times$ and $1.9 \times \mathrm{K}_{\mathrm{m}}$, respectively $\left(\mathrm{K}_{\mathrm{m}}=0.036\right.$ and $0.16 \mathrm{mM}$, respectively). AChE activity was measured using Type VI-S from Electrophorus electricus in the presence of $0.5 \mathrm{mM}$ 5,5'-dithiobis(2-nitrobenzoic acid) and 0.5 mM acetylthiocholine iodide, as described previously [51,52]. Enzymes and chemicals were purchased from Sigma-Aldrich (St. Louis, MO, USA).

\subsection{Analysis of Enzyme Inhibitions and Kinetics}

The inhibitory activities of the 24 COEs synthesized against MAO-A and MAO-B were first investigated at a concentration of $1.0 \mu \mathrm{M}$, and $\mathrm{IC}_{50}$ values were then determined. AChE inhibitory activities were also determined, except at a concentration of $10 \mu \mathrm{M}$. Time-dependent inhibitions and reversibilities were measured, and kinetic studies were performed on the most potent MAO-B inhibitors, i.e., COE-6, and COE-22, as previously described [53]. Kinetic experiments were carried out at five substrate and three inhibitor concentrations.

\subsection{Analysis of Inhibitor Reversibility}

The reversibilities of compounds COE-6, and COE-22 were analyzed while using a dialysis method after preincubating with MAO-B for $30 \mathrm{~min}$, as previously described [54]. Reversibilities were determined for COE-6, COE-22, lazabemide (a reversible MAO-B reference inhibitor), and pargyline (an irreversible MAO-B reference inhibitor) at $\sim 2 \times \mathrm{IC}_{50}$ concentrations, i.e., 0.004, 0.050, 0.080, and $0.040 \mu \mathrm{M}$, respectively. Relative activities of undialyzed $\left(\mathrm{A}_{U}\right)$ and dialyzed $\left(\mathrm{A}_{\mathrm{D}}\right)$ samples were used to determine the reversibilities.

\subsection{Computational Studies}

The three-dimensional (3D) structures of MAO-A (PDB ID: 2Z5X) and MAO-B (PDB ID: 2V5Z) were obtained from the Protein Data Bank. The protein preparation wizard available in the Schrödinger suite was used to optimize X-ray crystal structures [55,56]. MAO-A and MAO-B active sites contained nine and eight water molecules, respectively. The LigPrep tool was used to optimize ligand structures and generate possible tautomers and ionization states at physiological $\mathrm{pH}$. Docking simulations were 
carried out using the QM polarized ligand docking protocol available from Schrödinger Suite. While retaining the rigidities of protein structures, QM polarized ligand docking allows for ligands with a certain degree of conformational flexibility. Centers of mass of X-ray cognate ligands of MAO-A and MAO-B structures were used as references for the cubic grid center.

The QM-polarized ligand docking protocol that was implemented in Glide was used with default options. This protocol uses three computational steps, that is: a) a standard precision (SP) initial docking using Glide; b) calculation of QM partial charges of the docked ligand based; and, c) a SP re-docking phase for each ligand pose when considering computed QM based charges.

A Molecular Mechanics/Generalized Born Surface Area (MM-GBSA) method was added to the workflow for the calculation of the binding free energies $(\Delta G)$ between protein and ligands in order to estimate ligand-binding affinities. Such a method is implemented in Prime available in the Schrodinger software 2018-2 (New York, NY, USA) [57]. Provided that $\Delta \boldsymbol{E}_{M M}$ is the minimized energy of the ligand-protein complex, $\Delta G_{\text {solv }}$ is the solvation energy, and $\Delta G_{S A}$ is the binding energy of the surface area of compounds, with respect to MAO-A and MAO-B, $\Delta G_{b i n d}$ values were computed, as follows:

$$
\Delta G_{\text {bind }}=\Delta E_{M M}+\Delta G_{\text {solv }}+\Delta G_{S A}
$$

Obtained docking poses were minimized using Prime [57-59].

\section{Conclusions}

We evaluated the MAO-A, MAO-B, and AChE inhibitory activities of 24 previously synthesized chalcone oxime ethers (COE-1-COE-24). Most of the COEs exhibited significant and selective MAO-B inhibitory activity. Three compounds, viz., COE-6, COE-7 (chalcone-ketoxime ethers), and COE-22 (chalcone-chalconeoxime ethers), potently inhibited MAO-B. However, only COE-13 (chalcone-ketoxime ethers) significantly inhibited MAO-A and MAO-B. Notably, COE-22 inhibited $\bar{A} \mathrm{ChE}$ well and potently inhibited MAO-B. Both lead MAO-B inhibitors, COE-6 (chalcone-ketoxime ethers) and COE-22, contained a F substitution, which once again supports the notion that fluorine inclusion can have a profound effect on the biological activity. Reversibility and kinetics studies on COE-6 and COE-22 showed that both potently, selectively, reversibly, and competitively inhibited MAO-B. We hope this preliminary study on these novel COEs encourages medicinal chemists to further explore MAO inhibition and conduct biological activity studies.

Author Contributions: Conceptualization: T.M.R., B.M. and H.K.; biological activity: J.M.O.; kinetics: J.M.O.; docking analysis: A.R.T., N.G., O.N.; synthesis: R.C., R.P.S. (Rishi Pal Singh), M.S., R.P.S. (Raj Pal Singh); data curation: B.M., J.M.O.; writing—original draft preparation: B.M., T.M.R.; writing一review and editing: T.M.R., B.M. and H.K.; supervision: H.K.; funding acquisition: H.K. All authors have read and agreed to the published version of the manuscript.

Funding: This research was supported by the National Research Foundation of Korea (NRF) grant funded by the Republic of Korea government (NRF-2019R1A2C1088967) (to H.K.).

Conflicts of Interest: The authors declare no conflict of interest.

\section{References}

1. Querfurth, H.W.; LaFerla, F.M. Alzheimer's disease. N. Engl. J. Med. 2010, 362, 329-344. [CrossRef]

2. Mangialasche, F.; Solomon, A.; Winblad, B.; Mecocci, P.; Kivipelto, M. Alzheimer's disease: Clinical trials and drug development. Lancet Neurol. 2010, 9, 702-716. [CrossRef]

3. Zhang, H.-Y. One-compound-multiple-targets strategy to combat Alzheimer's disease. FEBS Lett. 2005, 579, 5260-5264. [CrossRef]

4. Youdim, M.B.H.; Buccafusco, J.J. Multi-functional drugs for various CNS targets in the treatment of neurodegenerative disorders. Trends Pharmacol. Sci. 2005, 26, 27-35. [CrossRef]

5. Mathew, B.; Parambi, D.G.T.; Mathew, G.E.; Uddin, M.S.; Inasu, S.T.; Kim, H.; Marathakam, A.; Unnikrishnan, M.K.; Carradori, S. Emerging therapeutic potentials of dual-acting MAO and AChE inhibitors in Alzheimer's and Parkinson's diseases. Arch. Pharm. Chem. Life Sci. 2019, 352, e1900177. [CrossRef] 
6. Bolognesi, M.L.; Matera, R.; Minarini, A.; Rosini, M.; Melchiorre, C. Alzheimer's disease new approaches to drug discovery. Curr. Opin. Chem. Biol. 2009, 13, 303-308. [CrossRef]

7. Bolognesi, M.L.; Cavalli, A.; Valgimigli, L.L.; Bartolini, M.; Rosini, M.; Andrisano, V.; Recanatini, M.; Melchiorre, C. Multi-target-directed drug design strategy: From a dual binding site acetylcholinesterase inhibitor to a trifunctional compound against Alzheimer's disease. J. Med. Chem. 2007, 50, 6446-6449. [CrossRef]

8. Youdim, M.B.H.; Edmondson, D.; Tipton, K.F. The therapeutic potential of monoamine oxidase inhibitors. Nat. Rev. Neurosci. 2006, 7, 295-309. [CrossRef]

9. Youdim, M.B.H.; Maruyama, W.; Naoi, M. Neuropharmacological, neuroprotective and amyloid precursor processing properties of selective MAO-B inhibitor antiparkinsonian drug, rasagiline. Drugs Today 2005, 41, 369-391. [CrossRef]

10. Cavalli, A.; Bolognesi, M.L.; Capsoni, S.; Andrisano, V.; Bartolini, M.; Margotti, E.; Cattaneo, A.; Recanatini, M.; Melchiorre, C. A small molecule targeting the multifactorial nature of Alzheimer's disease. Angew. Chem. Int. 2007, 46, 3689-3692. [CrossRef]

11. Van der Schyf, C.J.; Geldenhuys, W.J.; Youdim, M.B.H. Multifunctional drugs with different CNS targets for neuropsychiatric disorders. J. Neurochem. 2006, 99, 1033-1048. [CrossRef] [PubMed]

12. Dimmock, J.R.; Elias, D.W.; Beazely, M.A.; Kandepu, N.M. Bioactivities of chalcones. Curr. Med. Chem. 1999, 6, 1125-1149. [PubMed]

13. Mathew, B.; Suresh, J.; Anbazhagan, S.; Paulraj, J.; Krishnan, G.K. Heteroaryl chalcones: Mini review about their therapeutic voyage. BioMed. Prev. Nutr. 2014, 4, 451-458. [CrossRef]

14. Jandial, D.D.; Blair, C.A.; Zhang, S.; Krill, L.S.; Zhang, Y.B.; Zi, X. Molecular targeted approaches to cancer therapy and prevention using chalcones. Curr. Cancer Drug Targets 2014, 14, 181-200. [CrossRef]

15. Singh, P.; Anand, A.; Kumar, V. Recent developments in biological activities of chalcones: A mini review. Eur. J. Med. Chem. 2014, 85, 758-777. [CrossRef]

16. Mahapatra, D.K.; Bharti, S.K.; Asati, V. Chalcone scaffold as anti-infective agents: Structural and molecular target perspectives. Eur. J. Med. Chem. 2015, 101, 496-524. [CrossRef]

17. Mathew, B.; Haridas, A.; Suresh, J.; Mathew, G.E.; Ucar, G.; Jayaprakash, V. Monoamine oxidase inhibitory actions of chalcones: A mini review. Cent. Nerv. Syst. Agents Med. Chem. 2016, 16, 120-136. [CrossRef]

18. Chimenti, F.; Fioravanti, R.; Bolasco, A.; Chimenti, P.; Secci, D.; Rossi, F.; Yáñez, M.; Orallo, F.; Ortuso, F.; Alcaro, S. Chalcones: A valid scaffold for monoamine oxidases inhibitors. J. Med. Chem. 2009, 52, 2818-2824. [CrossRef]

19. Robinson, S.J.; Petzer, J.P.; Petzer, A.; Bergh, J.J.; Lourens, A.C.U. Selected furanochalcone as inhibitors of monoamine oxidase. Bioorg. Med. Chem. Lett. 2013, 23, 4985-4989. [CrossRef]

20. Jo, G.; Ahn, S.; Kim, B.G.; Park, H.R.; Kim, Y.H.; Cho, A.H.; Koh, D.; Chong, Y.; Ahn, H.; Lim, Y. Chromenyl chalcones with inhibitory effects on monoamine oxidase B. Bioorg. Med. Chem. 2013, 21,7890-7897. [CrossRef]

21. Morales-Camilo, N.; Salas, C.O.; Sanhueza, C.; Espinosa-Bustos, C.; Sepulveda-Boza, S.; Reyes-Parada, M.; Gonzalez-Nilo, F.; Caroli-Rezende, M.; Fierro, A. Synthesis, biological evaluation, and molecular simulation of chalcones and aurones as selective MAO-B inhibitors. Chem. Biol. Drug Des. 2015, 85, 685-695. [CrossRef] [PubMed]

22. Choi, J.W.; Jang, B.K.; Cho, N.; Park, J.H.; Yeon, S.K.; Ju, E.J.; Lee, Y.S.; Han, G.; Pae, A.M.; Kim, D.J.; et al. Synthesis of a series of unsaturated ketone derivatives as selective and reversible monoamine oxidase inhibitors. Bioorg. Med. Chem. 2015, 23, 6486-6496. [CrossRef] [PubMed]

23. Mathew, B. Unraveling the structural requirements of chalcone chemistry towards monoamine oxidase inhibition. Cent. Nerv. Syst. Agents Med. Chem. 2019, 19, 6-7. [CrossRef] [PubMed]

24. Mathew, B.; Mathew, G.E.; Uçar, G.; Baysal, I.; Suresh, J.; Vilapurathu, J.K.; Prakasan, A.; Suresh, J.K.; Thomas, A. Development of fluorinated methoxylated chalcones as selective monoamine oxidase-B inhibitors: Synthesis, biochemistry and molecular docking studies. Bioorg. Chem. 2015, 62, 22-29. [CrossRef] [PubMed]

25. Mathew, B.; Uçar, G.; Yabanoğlu-Çiftçi, S.; Baysal, I.; Suresh, J.; Mathew, G.E.; Vilapurathu, J.K.; Nadeena, A.M.; Nabeela, P.; Lakshmi, V.; et al. Development of fluorinated thienylchalcones as monoamine oxidase-b inhibitors: Design, synthesis, biological evaluation and molecular docking studies. Lett. Org. Chem. 2015, 12, 605-613. [CrossRef] 
26. Mathew, B.; Mathew, G.E.; Uçar, G.; Baysal, I.; Suresh, J.; Mathew, S. Potent and selective monoamine oxidase-b inhibitory activity: Fluoro- vs trifluoromethyl-4-hydroxylated chalcone derivatives. Chem. Biodivers. 2016, 13, 1046-1052. [CrossRef]

27. Mathew, B.; Haridas, A.; Uçar, G.; Baysal, I.; Adeniyi, A.A.; Soliman, M.E.S.; Joy, M.; Mathew, G.E.; Lakshmanan, B.; Jayaprakash, V. Exploration of chlorinated thienyl chalcones: A new class of monoamine oxidase-B inhibitors. Int. J. Biol. Macromol. 2016, 91, 680-695. [CrossRef]

28. Mathew, B.; Haridas, A.; Uçar, G.; Baysal, I.; Joy, M.; Mathew, G.E.; Lakshmanan, B.; Jayaprakash, V. Synthesis, biochemistry, and computational studies of brominated thienyl chalcones: A new class of reversible MAO-B inhibitors. ChemMedChem 2016, 11, 1161-1171. [CrossRef]

29. Mathew, B.; Uçar, G.; Mathew, G.E.; Mathew, S.; Purapurath, P.K.; Moolayil, F.; Mohan, S.; Varghese Gupta, S. Monoamine oxidase inhibitory activity: Methyl- versus chloro-chalcone derivatives. ChemMedChem 2016, 11, 2649-2655. [CrossRef]

30. Sasidharan, R.; Manju, S.L.; Uçar, G.; Baysal, I.; Mathew, B. Identification of indole based chalcones: Discovery of potent, selective and reversible class of MAO-B inhibitors. Arch. Pharm. Chem. Life Sci. 2016, 349, 627-637. [CrossRef]

31. Mathew, B.; Uçar, G.; Raphael, C.; Mathew, G.E.; Joy, M.; Machaba, K.E. Characterization of thienylchalcones as hMAO-B inhibitors: Synthesis, biochemistry and molecular dynamics studies. ChemistrySelect 2017, 2, 11113-11119. [CrossRef]

32. Sasidharan, R.; Baek, S.C.; Manju, S.L.; Kim, H.; Mathew, B. Imidazole bearing chalcones as new class of monoamine oxidase inhibitors. Biomed. Pharmacother. 2018, 106, 8-13. [CrossRef] [PubMed]

33. Suresh, J.; Baek, S.C.; Ramakrishnan, S.P.; Kim, H.; Mathew, B. Discovery of potent and reversible MAO-B inhibitors as furanochalcones. Int. J. Biol. Macromol. 2018, 108, 660-664. [CrossRef]

34. Mathew, B.; Baek, S.C.; Parambi, D.G.T.; Lee, J.P.; Mathew, G.E.; Jayanthi, S.; Devaraji, D.; Raphael, C.; Vinod, D.; Kondarath, S.S.; et al. Potent and highly selective dual-targeting monoamine oxidase-B inhibitors: Fluorinated chalcones of morpholine versus imidazole. Arch. Pharm. Chem. Life Sci. 2019, 352, e1800309. [CrossRef]

35. Shalaby, R.; Petzer, J.P.; Petzer, A.; Aahraf, U.M.; Atari, E.; Alasmari, F.; Kumarasamy, S.; Sari, Y.; Khali, A. SAR and molecular mechanism studies of monoamine oxidase inhibition by selected chalcone analogs. J. Enzym. Inhib. Med. Chem. 2019, 34, 863-876. [CrossRef]

36. Lakshminarayan, B.; Baek, S.C.; Kannappan, N.; Mangiatordi, G.F.; Nicolotti, O.; Subburaju, T.; Kim, H.; Mathew, B. Ethoxylated head of chalcones as a new class of multi-targeted MAO inhibitors. ChemistrySelect 2019, 4, 6614-6619. [CrossRef]

37. Reeta Baek, S.C.; Lee, J.P.; Rangarajan, T.M.; Ayushee; Singh, R.P.; Singh, M.; Mangiatordi, G.F.; Nicolotti, O.; Kim, H.; Mathew, B. Ethyl acetohydroxamate incorporated chalcones: Unveiling a novel class of chalcones for multitarget monoamine oxidase-B inhibitors against Alzheimer's disease. CNS Neurol. Disord. Drug Targets 2019, 8, 643-654.

38. Johnson, S.M.; Petrassi, H.M.; Palaninathan, S.K.; Mohamedmohaideen, N.N.; Purkey, H.E.; Nichols, C.; Chiang, K.P.; Walkup, T.; Sacchettini, J.C.; Sharpless, K.B.; et al. Bisaryloxime ethers as potent inhibitors of transthyretin amyloid fibril formation. J. Med. Chem. 2005, 48, 1576-1587. [CrossRef]

39. Tsuchiya, K.; Kondo, M.; Kida, M.; Nakao, M.; Iwahi, T.; Nishi, T.; Noji, Y.; Takeuchi, M.; Nozaki, Y. Cefmenoxime (SCE-1365), a novel broad-spectrum cephalosporin: In vitro and in vivo antibacterial activities. Antimicrob. Agents Chemother. 1981, 19, 56-65. [CrossRef]

40. Shibl, A.M.; Ishag, A.H.; Durgham, S.M. Comparative in vitro antibacterial activity of aztreonam against clinical isolates of gram-negative bacteria. Chemotheraphy 1989, 35, 72-76. [CrossRef]

41. Bryskier, A. Roxithromycin: Review of its antimicrobial activity. J. Antimicrob. Chemother. 1998, 41, 1-21. [CrossRef] [PubMed]

42. Carty, E.; Macey, M.; Mccartney, S.A.; Rampton, D.S. Ridogrel, a dual thromboxane synthase inhibitor and receptor antagonist: Anti-inflammatory profile in inflammatory bowel disease. Aliment. Pharmacol. Ther. 2000, 14, 807-817. [CrossRef] [PubMed]

43. van Hoogdalem, E.J.; van den Hoven, W.E.; Terpstra, I.J.; van Zijtveld, J.; Verschoor, J.S.C.; Visser, J.N. Nail penetration of the antifungal agent oxiconazole after repeated topical application in healthy volunteers, and the effect of acetylcysteine. Eur. J. Pharm. Sci. 1997, 5, 119-127. [CrossRef] 
44. Strupczewski, J.T.; Allen, R.C.; Gardner, B.A.; Schmid, B.L.; Stache, U.; Glamkowski, E.J.; Jones, M.C.; Ellis, D.B.; Huger, F.P.; Dunn, R.W. Synthesis and neuroleptic activity of 3-(1-substituted-4-piperidinyl)-1,2-benzisoxazoles. J. Med. Chem. 1985, 28, 761-769. [CrossRef] [PubMed]

45. Reeta Rajendran, V.; Rangarajan, T.M.; Ayushee; Singh, R.P.; Singh, M. Synthesis of novel chalcones through palladium-catalyzed C-O cross-coupling reaction of bromo-chalcones with ethyl acetohydroxamate and their antiplasmodial evaluation against Plasmodium falcipuram in vitro. Bioorg. Chem. 2019, 86, 631-640. [CrossRef]

46. Reeta Rangarajan, T.M.; Kaushik, K.; Singh, R.P.; Singh, M.; Singh, R.P. Efficient solvent- and temperature-tuned access to aldoxime ethers and phenolic functions by Pd-catalyzed C-O cross-coupling of aldoximes with aryl bromides and bromo-chalcones. New J. Chem. 2020, 44, 1326-1336. [CrossRef]

47. Reeta Rangarajan, T.M.; Singh, R.P.; Singh, M. An easy access to oxime ethers by Pd-catalyzed C-O cross-coupling of activated aryl bromides with ketoximes and chalcone oximes. Chin. J. Chem. 2020, 38, 830-836.

48. Mathew, B.; Carradori, S.; Guglielmi, P.; Uddin, M.S.; Kim, H. New aspects of monoamine oxidase-B inhibitors. The key role of halogens to open the golden door. Curr. Med. Chem. 2020, 27, 1-17. [CrossRef]

49. Mangiatordi, G.F.; Alberga, D.; Pisani, L.; Gadaleta, D.; Trisciuzzi, D.; Farina, R.; Carotti, A.; Lattanzi, G.; Catto, M.; Nicolotti, O. A rational approach to elucidate human monoamine oxidase molecular selectivity. Eur. J. Pharm. Sci. 2017, 101, 90-99. [CrossRef]

50. Mathew, B.; Baek, S.C.; Parambi, D.G.T.; Lee, J.P.; Joy, M.; Rilda, P.R.A.; Randev, R.V.; Nithyamol, P.; Vijayan, V.; Inasu, S.T.; et al. Selected aryl thiosemicarbazones as a new class of multi-targeted monoamine oxidase inhibitors. MedChemComm 2018, 9, 1871-1881. [CrossRef]

51. Lee, H.W.; Ryu, H.W.; Kang, M.G.; Park, D.; Oh, S.R.; Kim, H. Potent selective monoamine oxidase B inhibition by maackiain, a pterocarpan from the roots of Sophora flavescens. Bioorg. Med. Chem. Lett. 2016, 26, 4714-4719. [CrossRef] [PubMed]

52. Baek, S.C.; Lee, H.W.; Ryu, H.W.; Kang, M.G.; Park, D.; Kim, S.H.; Cho, M.L.; Oh, S.R.; Kim, H. Selective inhibition of monoamine oxidase A by hispidol. Bioorg. Med. Chem. Lett. 2018, 15, 584-588. [CrossRef] [PubMed]

53. Ellman, G.L.; Courtney, K.D.; Andres, V.; Feather-Stone, R.M., Jr. A new and rapid colorimetric determination of acetylcholinesterase activity. Biochem. Pharmacol. 1961, 7, 88-95. [CrossRef]

54. Baek, S.C.; Park, M.H.; Ryu, H.W.; Lee, J.P.; Kang, M.G.; Park, D.; Park, C.M.; Oh, S.R.; Kim, H. Rhamnocitrin isolated from Prunus padus var. seoulensis: A potent and selective reversible inhibitor of human monoamine oxidase A. Bioorg. Chem. 2018, 28, 317-325. [CrossRef] [PubMed]

55. Son, S.Y.; Ma, J.; Kondou, Y.; Yoshimura, M.; Yamashita, E.; Tsukihara, T. Structure of human monoamine oxidase A at 2.2-A resolution: The control of opening the entry for substrates/inhibitors. Proc. Natl. Acad. Sci. USA 2008, 105, 5739-5744. [CrossRef] [PubMed]

56. Binda, C.; Wang, J.; Pisani, L.; Caccia, C.; Carotti, A.; Salvati, P.; Edmondson, D.E.; Mattevi, A. Structures of human monoamine oxidase B complexes with selective non-covalent inhibitors: Safinamide and coumarin analogs. J. Med. Chem. 2007, 50, 5848-5852. [CrossRef]

57. Schrödinger Release 2018-2, Prime; Schrödinger, LLC: New York, NY, USA, 2018.

58. Schrödinger Release 2018-2: Glide; Schrödinger, LLC: New York, NY, USA, 2018.

59. Genheden, S.; Ryde, U. The MM/PBSA and MM/GBSA methods to estimate ligand-binding affinities. Expert Opin. Drug Discov. 2015, 10, 449-461. [CrossRef]

Sample Availability: Samples of the compounds are available from the authors. 